\title{
Determination of soil pH by using digital image processing technique
}

\author{
Vinay Kumar', Binod Kumar Vimal', Rakesh Kumar², Rakesh Kumar ${ }^{3}$ and Mukesh \\ Kumar $^{4}$ \\ ${ }^{1}$ Krishi Vigyan Kendra, Munger, Bihar Agricultural University, Sabour-813 210, Bhagalpur (Bihar), INDIA \\ ${ }^{2}$ Bihar Agricultural University, Sabour-813 210, Bhagalpur (Bihar), INDIA \\ ${ }^{3}$ Indian Council of Agricultural Research- Research Complex North Eastern Hill Region, Nagaland Centre \\ Jharnapani-797 106 (Nagaland), INDIA \\ ${ }^{4}$ Rajendra Agricultural University, Pusa-848 125, Samastipur (Bihar), INDIA \\ *Corresponding author. E-mail: rbinnu@gmail.com
}

Received: September 19, 2013; Revised received: November 16, 2013; Accepted; January 25, 2014

\begin{abstract}
Soil is recognized as one of the most valuable natural resource whose soil pH property used to describe the degree of acidity or basicity which affect nutrient availability and ultimately plant growth. Fifty soil samples were collected and their $\mathrm{pH}$ was determined by using digital image processing technique. Soil colour is visual perceptual property corresponding in humans to the categories i.e red, green, blue and others. Soil colours are the parts of visual perceptual property where digital values of red, green and blue (RGB) provide a clue for spectral signature capture of different $\mathrm{pH}$ in soil. For the capturing images, digital camera was used. Transformation of the multispectral image was carried out through TNT Mips spatial software. On the basis of RGB grey values, pixels properties and their digital correlations, results showed that there was a clear cut gap in grey values of colours in the images 1, 2, 3, 4,10,11,14 and 16. Ranges of soil $\mathrm{pH}$ and $\mathrm{pH}$ index values were 7.30-7.50 and 0.0070-0.0261, respectively in deep brown colour. Similarly, soil pH range varies from 6.80-7.04 and 5.58-6.58 in light yellowish and greenish colour respectively while their corresponding $\mathrm{pH}$ index values were $0.0071-0.0451$ and $0.0084-0.0239$. Thus soil pH range varies from 7.30-7.50, 6.80-7.04 and 5.58-6.58 in deep brown colour, light yellowish colour and greenish colour respectively.
\end{abstract}

Keywords: Colour, Digital images, Signature capture, Soil pH

\section{INTRODUCTION}

Soil is recognized as one of the most valuable natural resource. Soils are considered as the integral part of the landscape and their characteristics are largely governed by the landforms on which they have developed (Sawhney et al., 1992; Sharma et al., 1999). Systematic study of soils provides information on nature and type of soils for various uses (Sehgal, 1996). The $\mathrm{pH}$ in soils is an important concerning part of the soil health. $\mathrm{pH}$ is a term that is used to describe the degree of acidity or basicity. Soil acidity or alkalinity directly affects plant growth. If a soil is too sour or too sweet, plants cannot take up nutrients like nitrogen $(\mathrm{N})$, phosphorus $(\mathrm{P})$ and potassium $(\mathrm{K})$ (Buckman et al., 2002). Most nutrients that plants need are readily available when the $\mathrm{pH}$ of the soil solution ranges from 6.0 to 7.5. Below a pH of 6.0 (acid): Some nutrients such as nitrogen, phosphorus, and potassium are less available. Above a $\mathrm{pH}$ of 7.5 (very alkaline), Iron, manganese, and phosphorus are less available (Buckman et al., 2002). Wide range of soil colour; gray, black, white, red, brown and yellow is influenced by the content of organic matter, and due to the presence of water and oxidation state of iron and magnesium. Yellow or red soil indicates the presence of iron oxides. Dark brown or black colour in soil indicates that the soil has high organic matter content. Wet soil will appear darker than dry soil. Red and brown colours caused by oxidation. The presence of specific minerals can also affect soil colour.Manganese oxide causes a black colour, glauconitic makes the soil green, and calcite can make soil in arid regions appear white. Thus due to concentration of organic matters, presence of water and oxidation are influenced factors of $\mathrm{pH}$ and colour association (Bear, 1965).

Colour is the byproduct of the spectrum of light, as it is reflected or absorbed, as received by the human eye and processed by the human brain. When light hits objects i.e. soil, water, vegetation some of the wavelengths are absorbed and some are reflected, depending on the materials characteristics (Panda, 2009). However, digital camera receives the light in the terms of blue green and red bands. Red, green and blue are fundamental colours which is arranged in bands 321 (RGB), denote the wave lengths of electromagnetic radiation in spectrum band 3 $(0.63-0.69 \mu \mathrm{m})$, band $2(0.52-0.60 \mu \mathrm{m})$ and band 1 
$(0.45-0.52 \mu \mathrm{m})$ are distinctly represented by different wavelengths (Joseph, 2003). Reflected energy (Blue, green and red) from the various materials which was captured by digital cameras is responsible for signature capture of the object. Soil colours charts were derived though digital camera is the part of visual perceptual property where digital values of red, green and blue (RGB) provide a clue for spectral signature capture of $\mathrm{pH}$ in soil. Keeping above in view, the present investigation was conducted to determine the soil $\mathrm{pH}$ by using digital image processing technique.

\section{MATERIALS AND METHODS}

Soil samples were collected from Nathnagar block of Bhagalpur district and after processing soil $\mathrm{pH}$ were determined by using $\mathrm{pH}$ meter. Total fifty soil samples were analyzed for the present study and digital camera was used for capturing images (JPEG format). This JPEG format of images was converted into img. file for the purpose of digital value extraction and finally determined their digital values. Soil $\mathrm{pH}$ index value of each samples were analysed by using the following equation

$$
\text { Soil } p H \text { index }\left[\frac{\operatorname{Re} d / \text { Green }}{\text { Blue }}\right]
$$

Image transformation option was used for RGB layer analysis using TNT Mips (a geospatial analysis system providing a fully featured GIS, relational database management system, and automated image processing system with computer aided design, triangulated irregular network, surface modeling, map layout and innovative data publishing tools). Equation values and measured soil $\mathrm{pH}$ values were correlated. Determination of soil $\mathrm{pH}$ was based on digital image processing technique, in which digital photographs of the soil samples were used for the analysis of soil $\mathrm{pH}$.

\section{RESULTS AND DISCUSSION}

When light hits objects, some of the wavelengths are absorbed and some are reflected, depending on the materials in the object. However, soil is a part of an object and digital photograph of this object (soil) was taken through a camera, it received wavelengths corresponding to red green and blue colours. Bayer filter technique separate the colour bands for given information about the intensity of light in red, green, and blue (RGB) wavelength regions. Digital photographs or images were displayed with colour composites as well as incorporated wavelength bands. RGB colours and their mixed components in the image were associated with Intensity Hue-Saturation (IHS) system, where intensity related with total brightness of a colour, Hue refers to the dominant or average wavelength of light contributing to a colour and saturation specified the purity of colour relative to gray e.g. solid pink has low saturation than the solid crimson (Lillesand and Kiefer, 2004).

RGB+IHS yielded values provide very high accuracies for the calculation of the texture of the objects (Laliberte and Rango, 2008). In general, the multispectral transformation utilized a three-colour composite image from the original image data where the spectral information was separated into the hue and saturation components (Carper et al., 1990). Transformation of the multispectral image was carried out through TNT Mips spatial software in image correction option.

In whole images, colours of soil samples were taken through digital camera are different from one to another i.e. deep brown, light yellowish or greenish. There was clear cut difference in grey values of colours, when small sizes of image of soil samples were observed. Images 1, 2, 3, 4,10,11,14 and 16 showed deep brown, images 27, 33, 41 and 42 represents light brown and yellowish, images 43, 47, 49 and 50 represents greenish in colours (Fig.1).

Image data have been converted into geographical information system (GIS) environment for digital/pixel analysis using TNT Mips software. Digital values do

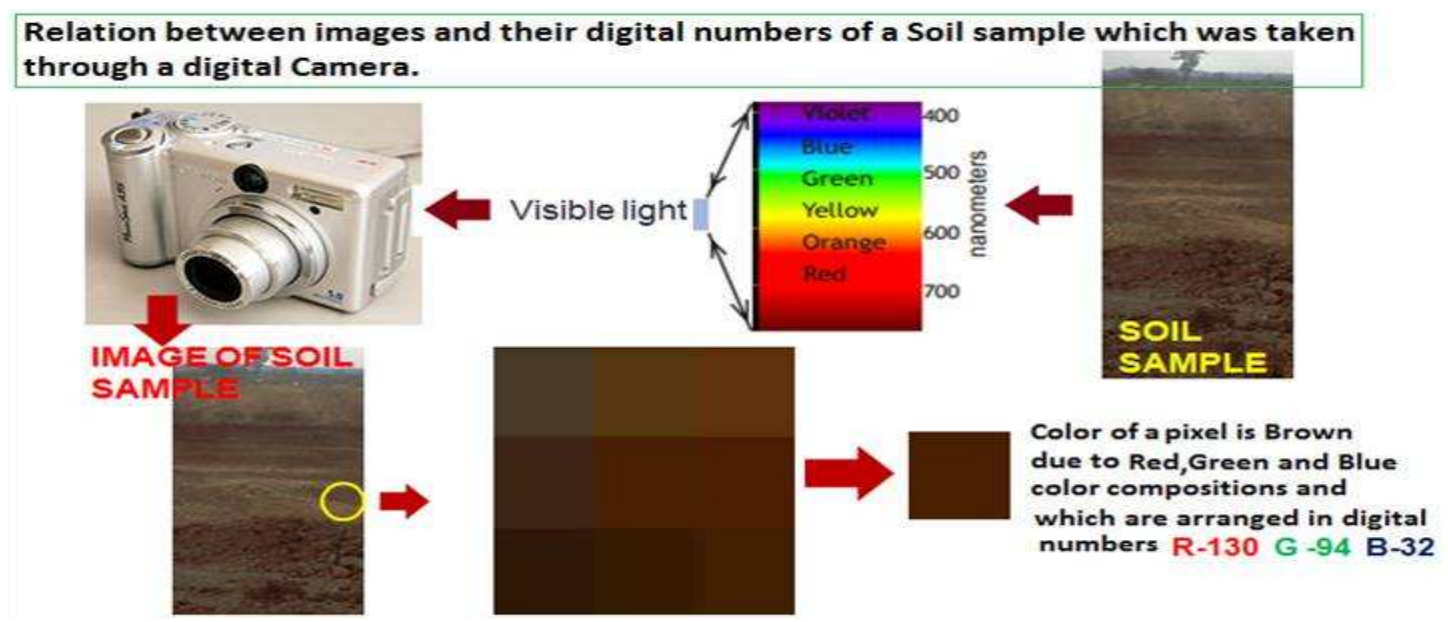

Plate 1. Flow Chart representing the digital value of the soil sample which has been identified through digital image processing of taken a photographs through digital camera during the sunlight. 


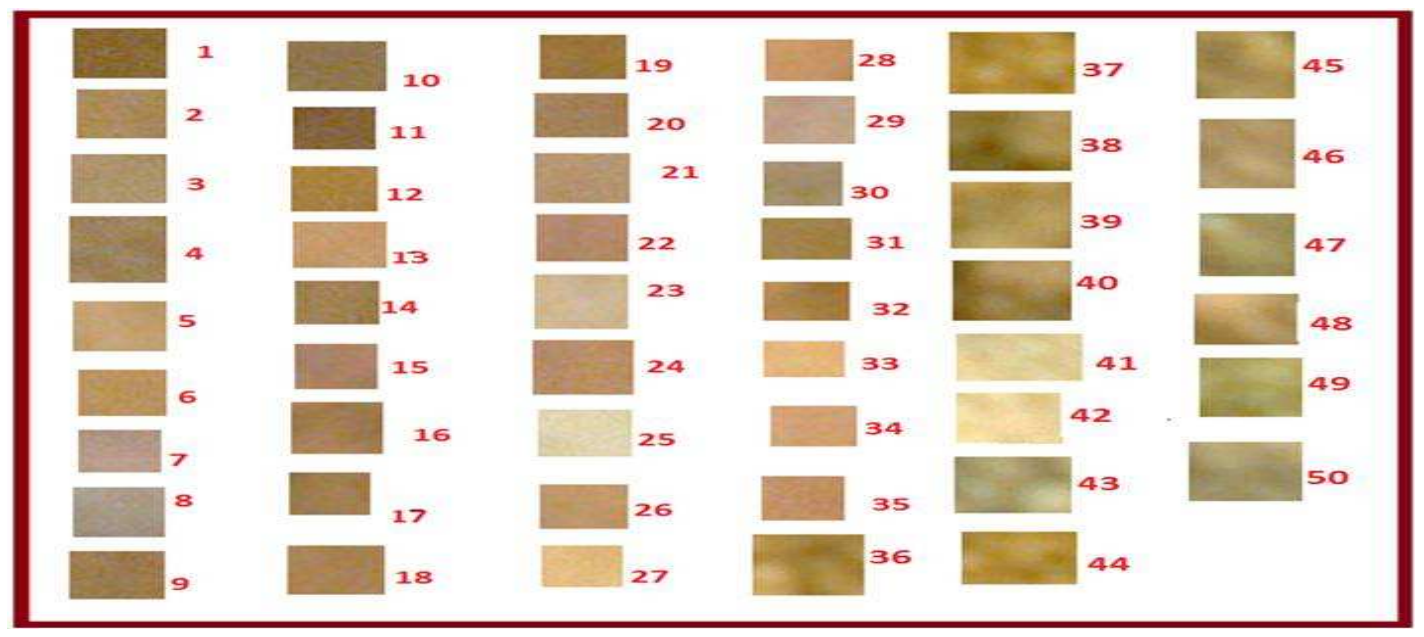

Fig. 1. Digital photographs of soil samples.

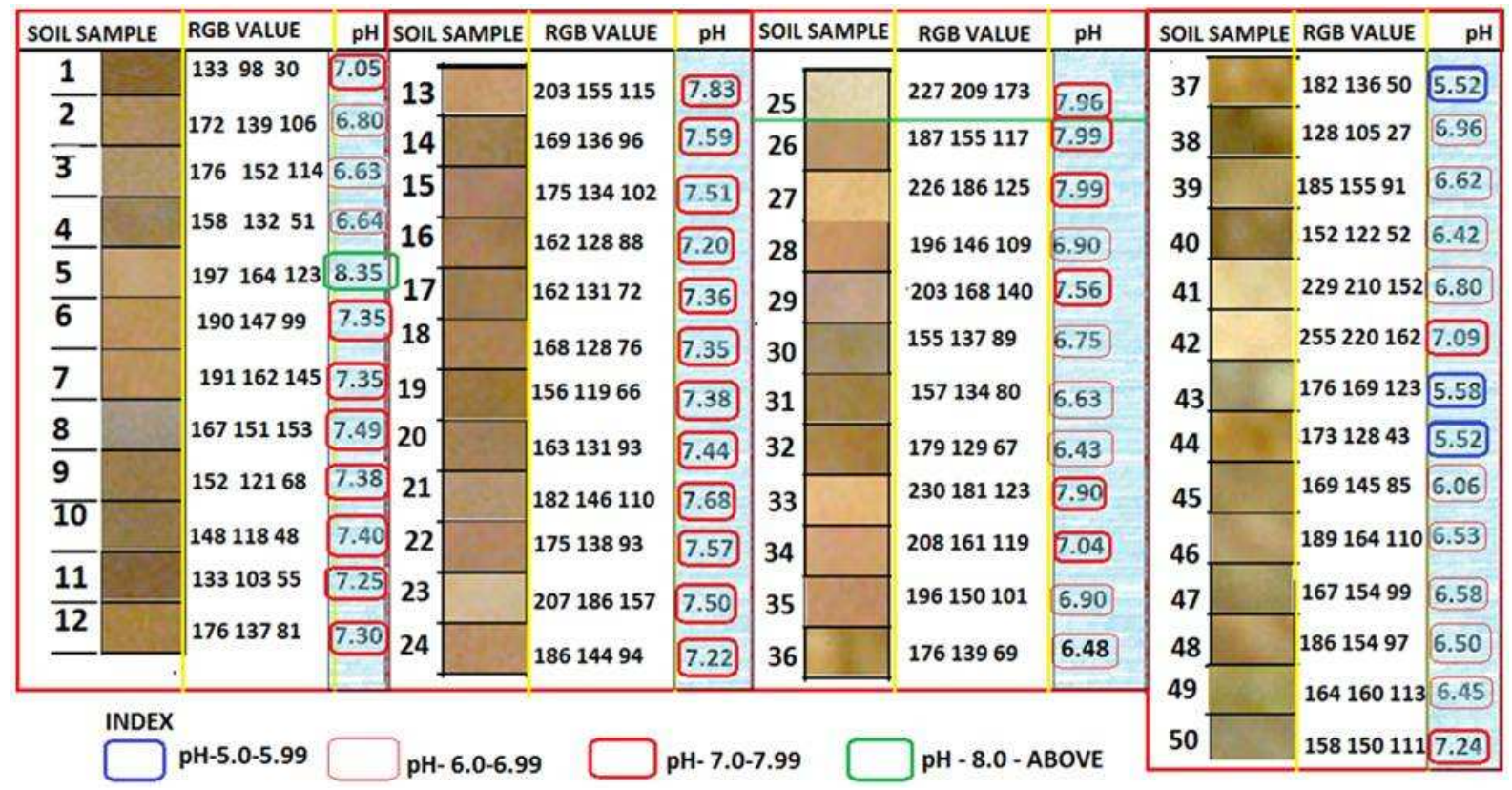

Fig. 2. Arrangement of digital values of $R G B$ colours of the photographs.

not match in blue, green and red layers of the digital images (Fig. 2). RGB values in deep brown coloured soil were $133-98-30$ to 207-186-157 and its value in light yellowish soil $128-105-27$ to $229-210-152$ whereas in greenish soil RGB value ranged 152-12252 to $189-164-113$.

Pixels and their digital values were demonstrated in graphs (Fig. 3).On the basis of RGB grey values, their pixels properties and digital correlations, Soil $\mathrm{pH}$ were analysed and plotted for result demonstration. Equation values (Soil pH index) of deep brown colours are different from light yellowish and greenish (Fig. 4). Soil $\mathrm{pH}$ values in deep brown colour were different from yellowish and other grey colours. Ranges of soil $\mathrm{pH}$ and $\mathrm{pH}$ index values were 7.30-7.50 and 0.00700.0261 , respectively in deep brown colour. Similarly, soil $\mathrm{pH}$ range varies from 6.80-7.04 and 5.58-6.58 in light yellowish and greenish colour respectively while their corresponding $\mathrm{pH}$ index values were 0.0071 0.0451 and $0.0084-0.0239$. Hence soils of Nathnagar block were alluvial and Tal land and colours under these land escape were light brown. However colours of soil samples in other geomorphologic areas may be black, grey and cotton black. This model may be helpful for signature capture of soil $\mathrm{pH}$ in different soil colour associations.

\section{Conclusion}

This model is based on digital image processing technique in Remote Sensing and Geographical Information System domain where digital photographs of the soil samples were used for soil $\mathrm{pH}$ determination. Digital photographs were collected during sunlight while photographs of the soil sample were taken in dark room for the purity of digital value of the spectra. RGB values in deep brown coloured soil 


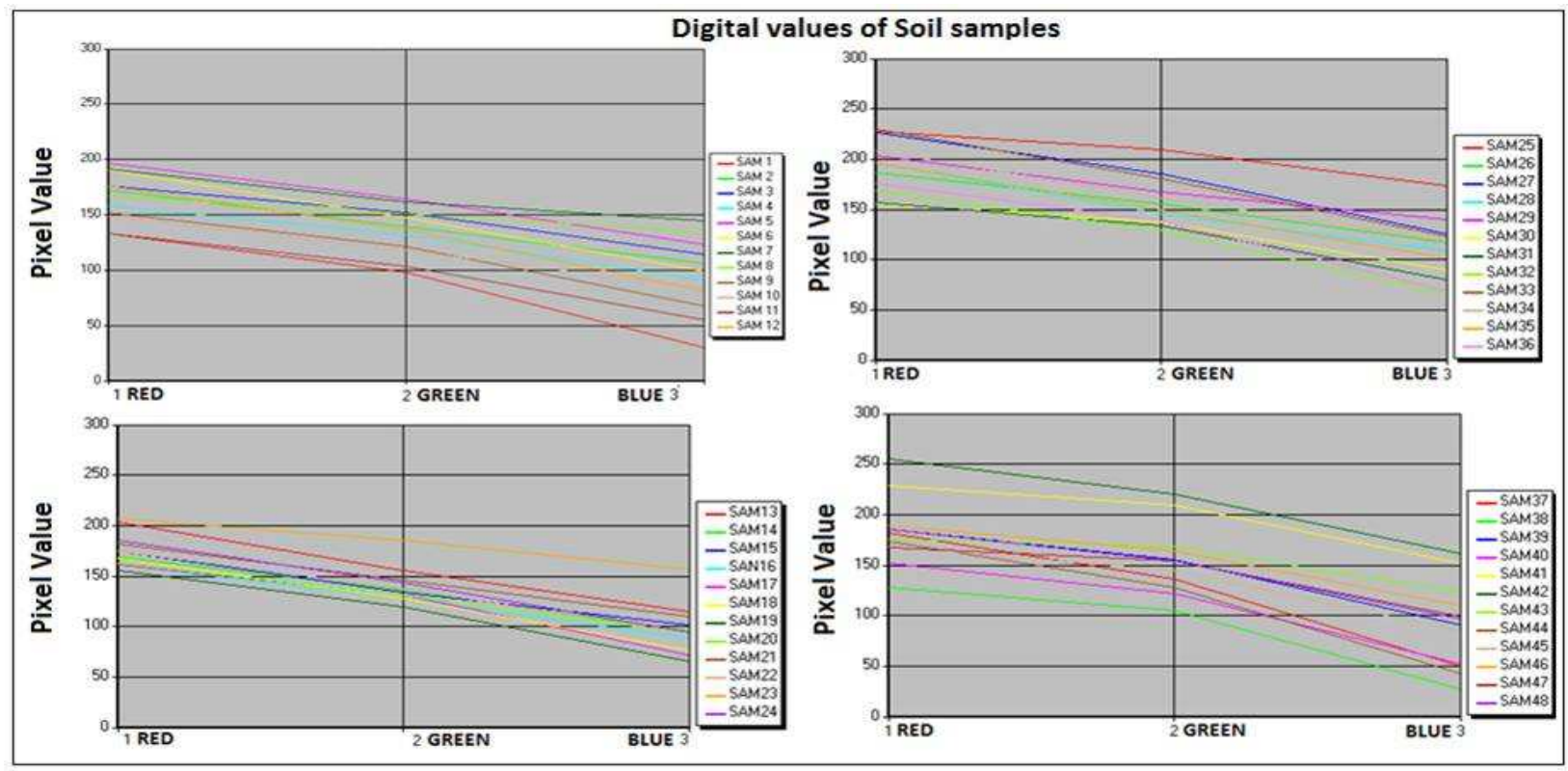

Fig. 3. Graphs of digital /pixels values of photographs of soil samples.

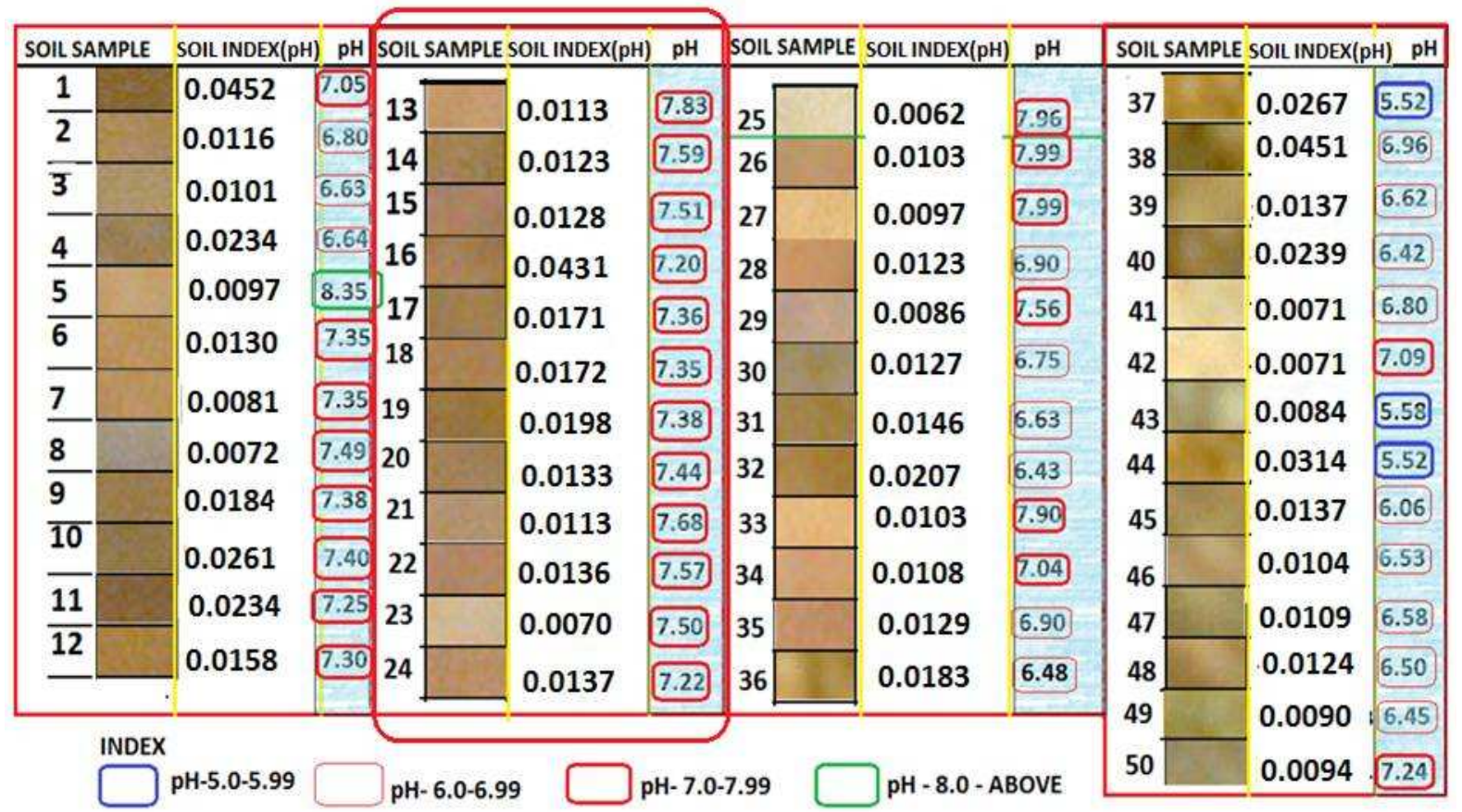

Fig. 4. Soil $p H$ and $p H$ index $(R / G / B)$ value derived through digital values of $R G B$.

were 133-98-30 to 207-186-157 and its value in light yellowish soil $128-105-27$ to $229-210-152$ whereas in greenish soil RGB value ranged $152-122-52$ to 189 164-113. Correlation between digital value and soil $\mathrm{pH}$ values should be helpful in determination of soil $\mathrm{pH}$ of different type of soils. Ranges of soil $\mathrm{pH}$ and $\mathrm{pH}$ index values were 7.30-7.50 and 0.0070-0.0261, respectively in deep brown colour. Similarly, soil $\mathrm{pH}$ range varies from 6.80-7.04 and 5.58-6.58 in light yellowish and greenish colour respectively while their corresponding $\mathrm{pH}$ index values were 0.0071-0.0451 and 0.00840.0239 . Thus soil $\mathrm{pH}$ range varies from 7.30-7.50, 6.80 -7.04 and 5.58-6.58 in deep brown colour, light yellowish colour and greenish colour respectively.

\section{ACKNOWLEDGEMENTS}

Authors are thankful to Dr. B.B. Mishra, University Prof.-cum-Chief Scientist, Department of Soil Science and Agricultural Chemistry, Bihar Agricultural University, Sabour, Bhagalpur, Bihar for his valuable suggestions during the research project work.

\section{REFERENCES}

Bear, F.E. (1965). Chemistry of the soil, (2nd edition) Reinhold Publication Corporation, New York.

Buckman, H.O. and Brady, N.C. Weil, R.R. (2002). The 
nature and properties of soils, $13^{\text {th }}$ Edition. Prentice Hall. Carper, W.J., Lillesand, T.M. and Kiefer, R.W. (1990). The use of intensity-hue-saturation transformations for merging SPOT panchromatic and multispectral image data. Photo-grammetric Engineering and Remote Sensing, 56(4): 459-467.

Joseph, G. (2003). Fundamentals of remote sensing, University Press, Hyderabad pp, 65-66.

Lillesand, M.T. and Kiefer, W.R. (2004). Remote sensing and Image Interpretation, Replica Press Pvt. Ltd. Pa: 545-546.
Panda, B.C. (2009). Remote sensing: Principle and application. Viva Books Pvt Ltd.

Sawhney, J.S., Verma, V.K., Sharma, B.D. and Sharma, P.K. (1992). Pedogenesis in relation to physiography in semi-arid and arid tracts of Punjab, India. Arid Soil Research and Rehabilitation, 6:93-103.

Sehgal, J. (1996). Pedology: Concepts and Applications, Kalyani publisers, New Delhi.

Sharma, B.D., Mukhopadhaya, S. and Sidhu, P.S. (1999). Microtopographic control on soil formation in the Punjab region, India. Geoderma, 81: 357-368. 